\title{
Soil-transmitted helminth infections and risk factors in preschool children in southern rural Lao People's Democratic Republic
}

\author{
Sengchanh Kounnavong ${ }^{\mathrm{a}, *}$, Manithong Vonglokham ${ }^{\mathrm{a}}$, Keonakhone Houamboun ${ }^{\mathrm{a}}$, \\ Peter Odermatt ${ }^{\mathrm{b}, \mathrm{c}}$, Boungnong Boupha ${ }^{\mathrm{a}}$ \\ a National Institute of Public Health, Ministry of Health, Vientiane, Lao People's Democratic Republic \\ b Department of Epidemiology and Public Health, Swiss Tropical \& Public Health Institute, Basel, Switzerland \\ c University of Basel, Basel, Switzerland
}

\section{A R T I C L E I N F O}

\section{Article history:}

Received 8 April 2010

Received in revised form

17 November 2010

Accepted 19 November 2010

Available online 1 February 2011

\section{Keywords:}

Intestinal parasites

Soil-transmitted helminths

Prevalence

Risk factors

Laos

Preschool children

\begin{abstract}
A B S T R A C T
The current widespread school-based control of soil-transmitted helminth (STH) infections is also advocated for preschool children. The objective of this study was to assess infection with STHs as well as their determinants in preschool children ( $<60$ months) in southern rural Lao People's Democratic Republic (Lao PDR). A cluster survey was carried out from October to December 2006 in three districts of Savannakhet Province. The prevalence of Ascaris lumbricoides, hookworm and Trichuris trichiura was 27.4\% (95\% CI 27.0-27.6\%), 10.9\% (95\% CI 10.7-11.0\%) and 10.9\% (95\% CI 10.7-11.1\%), respectively. Of the children studied, $28.4 \%$ had a monoparasitic infection and $9.3 \%$ had a polyparasitic infection. Older children had a higher risk for hookworm infection [odds ratio $(\mathrm{OR})=1.75,95 \% \mathrm{CI} 1.03-3.01 ; P=$ 0.041 ] and multiple infections $(\mathrm{OR}=1.81,95 \% \mathrm{CI} 1.01-3.20 ; P=0.044)$. Low socioeconomic status was associated with $A$. lumbricoides $(\mathrm{OR}=0.61,95 \% \mathrm{CI} 0.38-0.98 ; P=0.043$ ) and monoparasitic infections ( $\mathrm{OR}=0.62,95 \% \mathrm{Cl} 0.38-0.99 ; P=0.049$ ). In Lao PDR, deworming of preschool children is warranted. Preventive measures should address important risk factors. Health education regarding personal hygiene, appropriate water management and the construction and proper use of latrines are additional essential elements.
\end{abstract}

(c) 2010 Royal Society of Tropical Medicine and Hygiene. Published by Elsevier Ltd. All rights reserved.

\section{Introduction}

Globally, 130 countries are endemic for soil-transmitted helminth (STH) infections. Worldwide, 878 million schoolaged children and an estimated 386 million preschool children are at risk. ${ }^{1}$ The impact of STHs on health is due to their presence over a long period of time, their accumulation over time and exacerbation of malnutrition in children.

\footnotetext{
* Corresponding author. Present address: Health Research Division, National Institute of Public Health, Ministry of Health, Vientiane, Lao People's Democratic Republic.

Tel.: +856 2125 0670x301; fax: +85621214012.

E-mail address: sengchanhkounnavong@hotmail.com (S. Kounnavong).
}

Acute complications may occur, e.g. Ascaris lumbricoides infection may lead to appendicitis, ${ }^{2}$ duodenal ulcer, bowel obstruction, obstructive jaundice and hepatic abscesses, ${ }^{3}$ among others. STHs have also been associated with stunted growth and impaired cognitive function in children. ${ }^{4}$ Hookworm causes anaemia and is often associated with $A$. lumbricoides and Trichuris trichiura infections. ${ }^{5-7}$ In many cases children living in poverty are parasitised with all three STHs. ${ }^{8}$

In Lao People's Democratic Republic (Lao PDR), the prevalence of STH infection in school-aged children is extensive. A country wide study identified high prevalence rates of A. lumbricoides (34.9\%), hookworm (19.1\%) and $T$. trichiura (25.8\%). ${ }^{9}$ Several other studies conducted over the last few years documented a high prevalence of STHs in schoolchildren in different provinces. This information has 
led to the nationwide school-based deworming campaigns with albendazole $(400 \mathrm{mg}$ ) or mebendazole $(500 \mathrm{mg}$ ) once a year. ${ }^{10}$ Recent efforts have been directed at extending the intervention to preschool children aged 2-5 years as well as integrating vitamin A supplementation and vaccination. However, information on this age group is scarce. Thus, it is unclear whether the infection status of preschool children warrants regular preventive chemotherapy.

In the present study, the prevalence, intensity and determinants of infection as well as multiple infections with STHs in preschool-aged children were assessed. A random cluster survey was conducted in three rural districts of Savannakhet Province, Lao PDR. A stool sample from each child was examined for STHs, and the parents or legal care takers were interviewed regarding the presence of potential risk factors.

\section{Materials and methods}

\subsection{Study area}

Savannakhet Province is located some $650 \mathrm{~km}$ south of the capital city Vientiane. Sepol, Nong and Vilabury districts were selected for this study as they are among the poorest districts in Lao PDR. The districts are characterised by a scattered population with a high proportion of ethnic minorities, poor road conditions, and weak preventive and curative health services.

\subsection{Data collection}

This study was carried out between October and December 2006. A total of 1924 households in 80 randomly selected villages was visited by four survey teams. The households and villages were selected from the list of the 2005 census. The selection procedure followed the Expanded Programme on Immunization cluster sampling procedures. ${ }^{11}$ All children from aged 12-59 months (preschool) were included in the study. A questionnaire was filled out with the parents or legal guardian of the child. Prior to enrolment, oral informed consent was obtained from the parents or legal guardian of the child.

\subsection{Assessment of risk factors}

Socioeconomic and demographic information as well as information on risky behaviour of the child and other household members was collected. Potential risk factors were age, sex, mother's educational level, availability and use of a latrine in the household, and access to safe drinking water. Parents were asked to report on ill health of the child within the last 2 weeks.

Proxy markers of household socioeconomic status (SES) were household ownership of assets, housing characteristics, and education and occupation of the household head. Household assets comprised ownership of a car, motorcycle, radio, bicycle and animals such as cows, goats, pigs, horses, chickens and ducks. Household level characteristics included ownership of the house and type of roofing.

\subsection{Stool sample collection and analysis}

Labelled stool containers were provided to the parents of each child. The filled containers were collected the following morning and were transported by public bus in a cooled ice-box to the National Center for Laboratory and Epidemiology, Vientiane. Examination was performed within $24 \mathrm{~h}$ after collection. One Kato-Katz thick smear was performed on each stool sample. ${ }^{12}$ On each slide, eggs for each parasite species were counted and recorded. The intensity of infection [eggs per gram of stool (EPG)] was calculated for each parasite species. Individuals were categorised as having light, moderate or heavy infections based on the criteria of the WHO: ${ }^{13-15}$ A. lumbricoides: light, 0-4999 EPG; moderate, 5000-49 999 EPG; and heavy, $\geq 50000$ EPG; T. trichiura: light, 0-999 EPG; moderate, 1000-9999 EPG; and heavy, $\geq 10000$ EPG; and hookworm: light, 0-399 EPG; moderate, 400-2999 EPG; and heavy, $\geq 3000$ EPG.

\subsection{Data analysis}

Data were double-entered in Epi Info v.6.04 (CDC, Atlanta, GA, USA) and validated. SPSS statistical package v16.0 (SPSS Inc., Chicago, IL, USA) was used for analysis. Descriptive statistics were carried out. Frequencies were calculated for categorical variables (prevalence, etc.). In the univariate analysis, risk factors were associated with infection status. The odds ratio (OR) and 95\% CI were determined, and $\chi^{2}$ and Fisher's exact tests were used.

The household wealth index was the weighted sum of household characteristics and different consumer durables owned by the household. The weights for the variables in the index were generated using principal components analysis on the correlation matrix. ${ }^{16}$ In this survey, households were categorised into one of five equal-sized groups (quintiles) from the most poor to the least poor.

In the multiple logistic regression, the presence of helminth infection (outcome) was predicted with risk factors. Variables with a $P$-value of $<0.2$ in the univariate analysis were included as predictors. ORs and 95\% CIs were reported. $P$-values of $<0.05$ were regarded as significant.

\section{Results}

A total of 1504 preschool-aged children were identified in the 1924 households. In total, 570 children (37.9\%) provided a faecal specimen, of which 215 (37.7\%) specimens contained at least one STH. The prevalence of infection with A. lumbricoides, $T$. trichiura and hookworm was $27.4 \%, 10.9 \%$ and $10.9 \%$, respectively. Table 1 summarises the infection rates by risk group.

Regarding the intensity of infection, $11.2 \%$ of children had a heavy A. lumbricoides infection (Table 2). Infections with $T$. trichiura and hookworm were light or moderately intense; there were no children with heavy infection intensities with hookworm or T. trichiura. Infection with multiple parasite species was diagnosed in 53 children (9.3\%), comprising 7.5\% infected with two parasite species and $1.8 \%$ infected with all three parasite species. 
Table 1

Soil-transmitted helminth infections among 570 preschool children in southern Lao PDR

\begin{tabular}{|c|c|c|c|c|c|c|}
\hline \multirow[t]{2}{*}{ Characteristic } & \multirow[t]{2}{*}{ No. of children } & \multicolumn{5}{|c|}{ Children infected with [ $n(\%)]$ : } \\
\hline & & Ascaris lumbricoides & Hookworm & Trichuris trichiura & Single parasite & Multiple parasites \\
\hline \multicolumn{7}{|l|}{ Sex } \\
\hline Male & 277 & $68(24.5)$ & $32(11.6)$ & $27(9.7)$ & $77(27.8)$ & $23(8.3)$ \\
\hline Female & 293 & $88(30.0)$ & $30(10.2)$ & 35 (11.9) & $85(29.0)$ & $30(10.2)$ \\
\hline \multicolumn{7}{|l|}{ Age group (months) } \\
\hline $12-23$ & 146 & $34(23.3)$ & $4(2.7)$ & $6(4.1)$ & $41(28.1)$ & $1(0.7)$ \\
\hline $24-35$ & 145 & $47(32.4)$ & $20(13.8)$ & $21(14.5)$ & $43(29.7)$ & $19(13.1)$ \\
\hline $36-47$ & 155 & $35(22.6)$ & $19(12.3)$ & $16(10.3)$ & $37(23.9)$ & $14(9.0)$ \\
\hline $48-59$ & 124 & $40(32.3)$ & $19(15.3)$ & $19(15.3)$ & $41(33.1)$ & $19(15.3)$ \\
\hline \multicolumn{7}{|c|}{ Diarrhoea in last 2 weeks } \\
\hline Yes & 64 & $19(29.7)$ & $7(10.9)$ & $5(7.8)$ & $22(34.4)$ & $2(3.1)$ \\
\hline No & 506 & $137(27.1)$ & 55 (10.9) & $57(11.3)$ & $140(27.7)$ & $51(10.1)$ \\
\hline \multicolumn{7}{|l|}{ Location } \\
\hline Sepol & 351 & $107(30.5)$ & $31(8.8)$ & $34(9.7)$ & $107(30.5)$ & $30(8.5)$ \\
\hline Nong & 169 & $48(28.4)$ & $30(17.8)$ & $28(16.6)$ & $53(31.4)$ & $23(13.6)$ \\
\hline Vilabury & 50 & $1(2.0)$ & $1(2.0)$ & 0 & $2(4.0)$ & 0 \\
\hline \multicolumn{7}{|c|}{ No. of household members } \\
\hline$<4$ & 185 & $45(24.3)$ & $20(10.8)$ & $20(10.8)$ & $44(23.8)$ & $17(9.2)$ \\
\hline $5-7$ & 261 & $74(28.4)$ & $26(10.0)$ & $29(11.1)$ & $74(28.4)$ & $27(10.3)$ \\
\hline $8-10$ & 100 & $31(31.0)$ & $10(10.0)$ & $8(8.0)$ & $34(34.0)$ & $6(6.0)$ \\
\hline$>10$ & 24 & $6(25.0)$ & $6(25.0)$ & $5(20.8)$ & $10(41.7)$ & $3(12.5)$ \\
\hline \multicolumn{7}{|l|}{ Socioeconomic status } \\
\hline Most poor & 174 & $49(28.2)$ & $24(13.8)$ & $18(10.3)$ & $52(29.9)$ & $16(9.2)$ \\
\hline Very poor & 124 & $38(30.6)$ & $15(12.1)$ & $12(9.7)$ & $43(34.7)$ & $11(8.9)$ \\
\hline Poor & 81 & $26(32.1)$ & $6(7.4)$ & $8(9.9)$ & $19(23.5)$ & $9(11.1)$ \\
\hline Less poor & 97 & $22(22.7)$ & $7(7.2)$ & $11(11.3)$ & $25(25.8)$ & $7(7.2)$ \\
\hline Least poor & 94 & $21(22.3)$ & $10(10.6)$ & $13(13.8)$ & $23(24.5)$ & $10(10.6)$ \\
\hline \multicolumn{7}{|l|}{ Ownership of a latrine } \\
\hline Yes & 54 & $14(25.9)$ & $8(14.8)$ & $7(13.0)$ & $17(31.5)$ & $6(11.1)$ \\
\hline No & 516 & $142(27.5)$ & $54(10.5)$ & $55(10.7)$ & $145(28.1)$ & $47(9.1)$ \\
\hline \multicolumn{7}{|c|}{ Access to improved water sources } \\
\hline Yes & 86 & $22(25.6)$ & $11(12.8)$ & $9(10.5)$ & $26(30.2)$ & $6(7.0)$ \\
\hline No & 484 & $134(27.7)$ & $51(10.5)$ & $53(11.0)$ & $136(28.1)$ & $47(9.7)$ \\
\hline \multicolumn{7}{|c|}{ Mother's educational level } \\
\hline No education & 550 & $148(26.9)$ & $61(11.1)$ & $61(11.1)$ & $155(28.2)$ & $52(9.5)$ \\
\hline Primary and higher & 20 & $8(40.0)$ & $1(5.0)$ & $1(5.0)$ & $7(35.0)$ & $1(5.0)$ \\
\hline Total & 570 & $156(27.4)$ & $62(10.9)$ & $62(10.9)$ & $162(28.4)$ & $53(9.3)$ \\
\hline
\end{tabular}

Table 2

Infection intensity with soil-transmitted helminths by location in 570 preschool children in southern Lao PDR

\begin{tabular}{|c|c|c|c|c|}
\hline \multirow[t]{2}{*}{ Infection intensity } & \multicolumn{3}{|l|}{ Location } & \multirow[t]{2}{*}{ Total } \\
\hline & Sepol & Nong & Vilabury & \\
\hline \multicolumn{5}{|l|}{ Ascaris lumbricoides } \\
\hline No infection & $244(69.5)$ & $121(71.6)$ & $49(98.0)$ & $414(72.6)$ \\
\hline Light & $29(8.3)$ & $18(10.7)$ & $1(2.0)$ & $48(8.4)$ \\
\hline Moderate & $30(8.5)$ & $14(8.3)$ & - & $44(7.7)$ \\
\hline Heavy & $48(13.7)$ & $16(9.5)$ & - & $64(11.2)$ \\
\hline \multicolumn{5}{|l|}{ Hookworm } \\
\hline No infection & $320(91.2)$ & $139(82.2)$ & $49(98.0)$ & $508(89.1)$ \\
\hline Light & $25(7.1)$ & $27(16.0)$ & $1(2.0)$ & $53(9.3)$ \\
\hline Moderate & $6(1.7)$ & $3(1.8)$ & - & $9(1.6)$ \\
\hline Heavy & - & - & - & - \\
\hline \multicolumn{5}{|l|}{ Trichuris trichiura } \\
\hline No infection & $317(90.3)$ & $141(83.4)$ & $50(100.0)$ & $508(89.1)$ \\
\hline Light & $28(8.0)$ & $26(15.4)$ & - & $54(9.5)$ \\
\hline Moderate & $6(1.7)$ & $2(1.2)$ & - & $8(1.4)$ \\
\hline Heavy & - & - & - & - \\
\hline \multicolumn{5}{|l|}{ Mono/polyparasitism } \\
\hline No infection & $214(61.0)$ & $93(55.0)$ & $48(96.0)$ & $355(62.3)$ \\
\hline Single infection & $107(30.5)$ & $53(31.4)$ & $2(4.0)$ & $162(28.4)$ \\
\hline Double infection & $26(7.4)$ & $17(10.1)$ & - & $43(7.5)$ \\
\hline Triple infection & $4(1.1)$ & $6(3.6)$ & - & $10(1.8)$ \\
\hline Total & $351(100.0)$ & $169(100.0)$ & $50(100.0)$ & $570(100.0)$ \\
\hline
\end{tabular}

EPG: eggs per gram of stool.

a Based on the criteria of the WHO: ${ }^{13-15}$ A. lumbricoides: light, 0-4999 EPG; moderate, 5000-49 999 EPG; and heavy, $\geq 50$ 000 EPG; T. trichiura: light, 0-999 EPG; moderate, 1000-9999 EPG; and heavy, $\geq 10000$ EPG; and hookworm: light, 0-399 EPG; moderate, 400-2999 EPG; and heavy, $\geq 3000$ EPG. 
Table 3

Univariate analysis of the association between infection status with soil-transmitted helminths and potential risk factors in preschool children in southern Lao PDR

\begin{tabular}{|c|c|c|c|c|c|}
\hline \multirow[t]{2}{*}{ Characteristic } & \multicolumn{5}{|c|}{ Children infected with [odds ratio $(95 \% \mathrm{CI})$ ]: } \\
\hline & Ascaris lumbricoides & Hookworm & Trichuris trichiura & Single infection & Multiple infection \\
\hline Sex (male/female) & $1.3(0.9-1.9)$ & $0.8(0.5-1.4)$ & $1.5(0.7-2.1)$ & $1.1(0.7-1.5)$ & $0.7(0.4-1.3)$ \\
\hline \multicolumn{6}{|l|}{ Age group (months) } \\
\hline $12-23$ & 1 & 1 & 1 & 1 & 1 \\
\hline $24-35$ & $1.6(0.9-2.7)$ & $1.3(0.6-2.5)$ & $1.6(0.8-3.2)$ & $1.6(0.9-2.7)$ & $2.2(1.03-4.7)$ \\
\hline $36-47$ & $0.9(0.6-1.6)$ & $1.1(0.5-2.2)$ & $1.1(0.5-2.1)$ & $1.2(0.7-2.1)$ & $1.3(0.6-2.6)$ \\
\hline $48-59$ & $1.6(0.9-2.8)$ & $6.4(2.1-19.4)$ & $4.2(1.6-10.9)$ & $1.8(1.1-3.1)$ & $3.4(1.4-5.4)$ \\
\hline Had diarrhoea in the last 2 weeks (yes/no) & $0.9(0.5-1.56)$ & $0.9(0.4-2.3)$ & $1.4(0.6-3.8)$ & $0.8(0.4-1.3)$ & $3.2(0.7-13.6)$ \\
\hline \multicolumn{6}{|l|}{ Location } \\
\hline Sepol & 1 & 1 & 1 & 1 & 1 \\
\hline Nong & $0.05(0.01-0.3)$ & $0.21(0.03-1.58)$ & $3.9(2.3-6.7)$ & $0.08(0.02-0.35)$ & $1.29(0.71-2.34)$ \\
\hline Vilabury & $0.05(0.01-0.4)$ & $0.09(0.01-0.71)$ & & $0.08(0.02-0.34)$ & \\
\hline \multicolumn{6}{|l|}{ No. of household members } \\
\hline$<4$ & 1 & 1 & 1 & 1 & 1 \\
\hline $5-7$ & $0.84(0.32-2.21)$ & $2.75(0.98-7.73)$ & $2.17(0.73-6.45)$ & $1.60(0.62-4.17)$ & $2.02(0.51-7.98)$ \\
\hline $8-10$ & $1.04(0.39-2.77)$ & $3.00(0.97-9.30)$ & $2.11(0.73-6.06)$ & $2.05(0.83-5.03)$ & $1.64(0.43-6.25)$ \\
\hline$>10$ & $0.74(0.27-2.05)$ & $3.01(1.10-8.26)$ & $3.03(0.89-10.27)$ & $2.73(1.08-6.88)$ & $2.68(0.58-12.3)$ \\
\hline \multicolumn{6}{|l|}{ Socioeconomic status } \\
\hline Most poor & 1 & 1 & 1 & 1 & 1 \\
\hline Very poor & $0.73(0.41-1.32)$ & $1.53(0.56-4.21)$ & $1.25(0.53-2.96)$ & $0.99(0.48-2.02)$ & $0.93(0.35-2.47)$ \\
\hline Poor & $0.98(0.50-1.93)$ & $1.49(0.52-4.29)$ & $1.39(0.65-2.98)$ & $0.74(0.41-1.34)$ & $1.50(0.54-4.18)$ \\
\hline Less poor & $0.65(0.35-1.21)$ & $0.87(0.37-2.02)$ & $1.46(0.57-3.73)$ & $0.62(0.34-1.16)$ & $1.06(0.42-2.65)$ \\
\hline Least poor & $0.61(0.31-1.19)$ & $0.74(0.34-1.63)$ & $1.50(0.65-3.45)$ & $0.44(0.47-1.80)$ & $1.08(0.46-2.52)$ \\
\hline Ownership of a latrine (yes/no) & $1.08(0.57-2.05)$ & $0.67(0.3-1.4)$ & $0.8(0.34-1.85)$ & $1.27(0.68-2.31)$ & $1.34(0.53-3.40)$ \\
\hline Access to safe water (yes/no) & $1.1(0.6-1.8)$ & $0.8(0.4-1.6)$ & $1.05(0.4-2.2)$ & $0.90(0.53-1.52)$ & $0.68(0.28-1.68)$ \\
\hline \multicolumn{6}{|l|}{ Mother's educational level } \\
\hline No education & 1 & 1 & 1 & 1 & 1 \\
\hline Primary and higher & $1.81(0.73-4.52)$ & $0.42(0.06-3.21)$ & $0.42(0.06-3.21)$ & $1.34(0.52-3.47)$ & $0.55(0.07-4.35)$ \\
\hline
\end{tabular}

The prevalence of infection did not differ between boys and girls for any of the parasite species (Table 3 ), and multiple infections were not associated with sex $(\mathrm{OR}=0.7,95 \%$ CI 0.4-1.3). However, the risk of STH infection increased with age. Children aged 48-59 months had a 6.4 -fold (95\% CI 2.1-19.4) and 4.2-fold (95\% CI 1.6-10.9) increased risk for hookworm and T. trichiura infection, respectively, and a 1.8 -fold (95\% CI 1.1-3.1) and 3.4-fold (95\% CI 1.4-5.4) higher risk of a single and multiple infections, respectively. Trichuris trichiura was significantly more prevalent in Nong district compared with the other two locations $(\mathrm{OR}=3.9$, $95 \%$ CI 2.3-6.7). The other two parasite species were more frequently diagnosed in Sepol district, however the differences were not significant.

The number of household members was positively associated with infection status. Children in a household with more than 10 people had a 2.73 -fold $(95 \% \mathrm{CI}$ 1.08-6.88) increased risk for any STH infection compared with those households with less than 4 people. A significantly increased risk was also found for hookworm ( $\mathrm{OR}=$ $3.01,95 \%$ CI 1.10-8.26).

Latrine ownership, access to a safe water supply, and mother's educational level were not associated with parasite infection status.

Overall, $48.9 \%$ of the study subjects were stunted, $22.6 \%$ had acute malnutrition and $47.7 \%$ were anaemic.

In the multiple logistic regression analysis for A. lumbricoides infection, the following predictors were included: SES; family size; ownership of a latrine; mother's educational level; access to improved water sources; and age of children (Table 4). After adjustment, the only factor associated with $A$. lumbricoides was SES (OR $=0.61,95 \% \mathrm{CI}$ $0.38-0.98 ; P=0.043$ ).

None of the predicting variables (location of household, wealth index quintile, mother's educational level, number of members in households, and ownership of a latrine) were found to be associated with $T$. trichiura infection in the multiple logistic regression analysis.

The same procedure was performed for hookworm infection, monoinfection and multiple infections with the following variables: location of household; wealth index quintile; mother's educational level; ownership of a latrine; and age of the child. SES was associated with monoparasitic infection (OR $=0.62,95 \%$ CI $0.38-0.99 ; P$ $=0.049$ ). Older children had an increased risk of being infected with hookworm $(\mathrm{OR}=1.75,95 \% \mathrm{CI} 1.02-3.01$; $P=0.041)$ and having a multiple infection ( $\mathrm{OR}=1.81,95 \%$ CI 1.01-3.20; $P=0.044$ ).

\section{Discussion}

This cross-sectional study included 570 preschool children aged 12-59 months living in three rural remote districts of Savannakhet Province in southern Lao PDR. Although only approximately one-third (570/1504) of the eligible study participants submitted a stool sample, this number may be more representative of the local population in this poor remote setting compared with the national nutrition survey (2005) where only 200 samples were collected. ${ }^{17}$ It was found that nearly one-third of the children $(28.4 \%$ ) had a single parasite and $9.3 \%$ had a multiparasitic infection of two or three different species. Ascaris 
Table 4

Prediction of Ascaris lumbricoides, Trichuris trichiura and hookworm infections in preschool children $(n=570)$ with multiple logistic regression models in three districts of Savannakhet Province, Lao PDR, in 2006

\begin{tabular}{|c|c|c|c|c|}
\hline Variable $^{a}$ & Parameter estimate & Standard error of estimate & Odds ratio $(95 \% \mathrm{CI})$ & $P$-value \\
\hline \multicolumn{5}{|l|}{ Ascaris lumbricoides } \\
\hline Household wealth (least poor vs. most poor) & -0.489 & 0.241 & $0.61(0.38-0.98)$ & 0.043 \\
\hline \multicolumn{5}{|l|}{ Hookworm } \\
\hline Age of children ( $\geq 48$ months vs. $<48$ months) & 0.564 & 0.276 & $1.75(1.02-3.01)$ & 0.041 \\
\hline \multicolumn{5}{|l|}{ Single infection } \\
\hline Household wealth (least poor vs. most poor) & -0.474 & 0.241 & $0.62(0.38-0.99)$ & 0.049 \\
\hline \multicolumn{5}{|l|}{ Multiple infection } \\
\hline Age of children ( $\geq 48$ months vs. $<48$ months) & 0.598 & 0.297 & $1.81(1.01-3.20)$ & 0.044 \\
\hline
\end{tabular}

a Variables included in the model: age; family size; household wealth; ownership of a latrine; access to improved water sources; and mother's educational level.

lumbricoides was the most prevalent infection (27.4\%), whilst the other two parasite species reached a prevalence rate of $10.9 \%$. Ascaris lumbricoides was detected at heavy infection intensities. Older children had greater risk of infection with hookworm $(\mathrm{OR}=1.75,95 \%$ CI 1.03-3.01; $P=0.041)$ and of multiple infections $(\mathrm{OR}=1.81,95 \% \mathrm{CI}$ 1.01-3.20; $P=0.044)$. Low SES was associated with $A$. lumbricoides infection $(\mathrm{OR}=0.61,95 \% \mathrm{CI} 0.38-0.98 ; P=$ 0.043).

There is a paucity of information on infection and risk factors of STHs in preschool-aged children in general, and in Southeast Asia and Lao PDR in particular. To our knowledge, this is the first study in Lao PDR focusing on this age category. Previous studies have targeted school-aged children. In general they have diagnosed a higher infection prevalence than in this study. ${ }^{18-21}$ In Lao PDR, the prevalence of STHs in schoolchildren in urban areas was $38.1 \% 22$ and there was higher prevalence in rural areas up to $80 \% .{ }^{23,24}$ Exposure of older children to infection is higher as they express a different set of behaviours. In addition, older children accumulate infection during their lifetime.

Nearly $10 \%$ of the children in this study had a multiparasitic infection. Other studies in schoolchildren of resource-poor countries found positive associations between $A$. lumbricoides and $T$. trichiura infections and multiparasitism that was considerably higher than in this study. The limited resources and substantial logistical challenges of implementing studies in most rural communities did not allow a more rigorous diagnostic procedure to be employed. It is known that a single Kato-Katz smear performed on a single stool sample has a relatively low sensitivity. ${ }^{25}$ Therefore, it can be assumed that the true infection prevalence is higher than that documented here. In addition, the Kato-Katz technique does not allow diagnosis of a broader range of parasite species. Other infections, such as Strongyloides stercoralis, might have been of considerable importance as has previously been shown in school-aged children. ${ }^{26}$

This study focused on infection rather than morbidity due to STH infections, although parents and caretakers were asked to report episodes of ill health in the preceding 2 weeks of the study visit. The only health problem reported with notable frequency was diarrhoea (11.2\% of children had a diarrhoeal episode). However, these events could not be explained by a STH infection. Indeed, previous studies have shown that diarrhoea in preschool children is mainly due to viral infection. ${ }^{27}$
In this study, infection intensity of STHs was assessed as an indirect measure of morbidity. High-intensity infection with A. lumbricoides was frequent (11.2\%). Previous studies showed that this helminth is highly prevalent in schoolchildren in Lao PDR. ${ }^{9}$ The acute consequences of A. lumbricoides infection should not be underestimated. A recent case report of a 12 -year-old boy in northern Lao PDR with obstructive biliary ascariasis with cholangitis and hepatic abscesses documented the potential serious outcome of this infection. ${ }^{3}$

Trichuris trichiura and hookworm infection were identified at lower prevalence rates and no heavy infection intensities were recorded. However, there was a high prevalence of chronic, acute malnutrition and anaemia among the study subjects although there were no associations with STH infection. Other studies showed that co-infections of hookworm and either Schistosoma japonicum or T. trichiura were associated with higher levels of anaemia. $^{28}$

In addition to the three mentioned STH infections, other parasite eggs were also detected, such as Opisthorchis viverrini (17 cases), Enterobius vermicularis (2 cases), Hymenolepis sp. (1 case) and the protozoa Giardia lamblia (25 cases). However, there were only very few of these infections.

Risk factor analysis showed that household wealth was the only variable significantly associated with A. lumbricoides infection. Children of least poor households had a $39 \%$ risk reduction for an infection with $A$. lumbricoides compared with children from the poorest households, controlled for age, mother's educational level, family size, ownership of a latrine and access to safe water. It is noteworthy that this risk factor could be identified in a poor rural area where relatively little economic variability is present between households. Other studies have identified household economic level as a determinant for STH in children. ${ }^{29,30}$

In the multivariate analysis, hookworm infection was best predicted by age. Older children aged $\geq 48$ months had a 70\% increased risk for hookworm infection compared with their younger peers. Children's activities outside of the household increase with age, thus the risk of contact with infectious hookworm larvae on the ground increases. Results of the multivariate risk factor analysis for single and multiple infections were similar to the risk factors for A. lumbricoides and hookworm, respectively. This is most probably due to the fact that A. lumbricoides was by far 
the most frequently diagnosed parasite and that only hookworm infection showed an association with an examined risk factor.

We could not identify an association between ownership of a latrine or access to safe water sources and infection with a STH. Several reasons might be responsible for this. In this setting, only a very few households possessed a latrine. In addition, the latrines were of low quality and poorly maintained. It is conceivable that the conditions of these latrines and their number were insufficient to result in a clear health benefit such as the prevention of infection with STHs. Furthermore, preschool children, particularly younger ones, rarely use latrines. A study in Vietnam showed that the presence of latrines alone is not sufficient to reduce the prevalence of STH in a rural agricultural community if fresh faeces are used as fertiliser. ${ }^{31,32}$ In contrast, improper disposal of human waste and poor sanitation might be responsible for STHs in resource-poor settings. ${ }^{33}$

It was found that the intensity of infection with STHs was low in Vilabury district, which might be due to the small number of stool samples $(n=50)$ in this location compared with Sepol $(n=351)$ and Nong $(n=169)$ districts, and different infection rates among the three locations might be explained as Vilabury is located in a highland area compared with Sepol and Vilabury districts.

Preventive chemotherapy on a regular basis has been shown to reduce STHs in a cost-effective manner. ${ }^{10,34}$ Additional health promotion on hygienic practices is essential to assure long-term benefits. ${ }^{35}$ In Lao PDR, mass distribution of anthelminthic medicines in schools was started a few years ago. In 2006, schoolchildren from 13 of the total 17 provinces had been covered once per year, including Savannakhet province. In 2008, the school deworming campaign reached a national coverage rate of $95 \%$ for two treatment rounds per year. ${ }^{10}$

Given the infection prevalence and intensity identified in this study, the morbidity associated with these infections and the prevailing risk factors for STHs, preventive treatment is warranted in preschool-aged children. Therefore, in Lao PDR the school-based deworming programme should be extended to preschool children. ${ }^{36}$ Starting treatment early in life will ensure that children remain parasite free for longer. The challenge ahead is how best to reach preschool-aged children in rural communities. Ingenuity is required to identify new approaches for medicine delivery for this vulnerable age group.

Authors' contributions: SK, KH, BB and MV designed, planned and implemented the study, analysed the data and wrote the first draft; PO contributed to the study design, data analysis and the writing of the paper; SK, KH, MV, PO and BB revised the manuscript. All authors read and approved the final manuscript. SK is guarantor of the paper.

Acknowledgements: The authors thank UNICEF for financial support. They also thank Dr Khampheng Chomlasak and Mr Khambai Munnalath (National Centre for Laboratory and Epidemiology, Ministry of Health, Vientiane, Lao PDR) for technical and administrative assistance during the field survey and laboratory analysis; Mr Khamtan (Mahosot
Hospital, Vientiane, Lao PDR) for field data collection; and Dr Sommack Manivanh, Dr Dalaphone Sithideth, Dr Chanthaly Luangphaxay, Dr Ketmany Chanthakouman and Dr Sida Xayavong (National Institute of Public Health, Vientiane, Lao PDR) for assistance in field supervision during data collection. The work of all data collectors from the provincial and district levels as well as all study subjects is very highly appreciated.

Funding: The study was funded by UNICEF, Vientiane, Lao PDR.

Conflicts of interest: None declared.

Ethical approval: This study was approved by the National Ethics Committee for Health Research, Ministry of Health, Vientiane, Lao PDR. Authorities at province, district and village agreed with the study. Oral informed consent was obtained from parents or legal caretakers of the children.

\section{References}

1. WHO. Soil-transmitted helminthiasis. Progress report on number of children treated with anthelminthic drugs: an update towards the 2010 global target. Wkly Epidemiol Rec 2008; 82:237-52.

2. Misra SP, Dwivedi M, Misra V, Singh PA, Agarwal VK. Preoperative sonographic diagnosis of acute appendicitis caused by Ascaris lumbricoides. J Clin Ultrasound 1999;27:96-7.

3. Slesak G, Phanthavong P, Rasphone O, Luangxay K, Anoulakkham $\mathrm{P}$, Pahatsalang $\mathrm{V}$, et al. Obstructive biliary ascariasis with cholangitis and hepatic abscesses in Laos: a case report with gall bladder ultrasound video. J Infect 2007;54:e233-5.

4. Hall A. Micronutrient supplements for children after deworming. Lancet Infect Dis 2007;7:297-302.

5. Midzi N, Mtapuri-Zinyowera S, Mapingure MP, Sangweme D, Chirehwa MT, Brouwer KC, et al. Consequences of polyparasitism on anaemia among primary school children in Zimbabwe. Acta Trop 2010;115:103-11.

6. Sousa-Figueiredo JC, Basáñez MG, Mgeni AF, Khamis IS, Rollinson D, Stothard JR. A parasitological survey, in rural Zanzibar, of preschool children and their mothers for urinary schistosomiasis, soil-transmitted helminthiases and malaria, with observations on the prevalence of anaemia. Ann Trop Med Parasitol 2008;102:679-92.

7. Wani SA, Ahmad F, Zargar SA, Dar ZA, Dar PA, Tak H, et al. Soiltransmitted helminths in relation to hemoglobin status among school children of the Kashmir Valley. J Parasitol 2008;94:591-3.

8. Bethony J, Brooker S, Albonico M, Geiger SM, Loukas A, Diemert D, et al. Soil-transmitted helminth infections: ascariasis, trichuriasis, and hookworm. Lancet 2006;367:1521-32.

9. Rim HJ, Chai JY, Min DY, Cho SY, Eom KS, Hong SJ, et al. Prevalence of intestinal parasite infections on a national scale among primary schoolchildren in Laos. Parasitol Res 2003;91:267-72.

10. Phommasack B, Saklokham K, Chanthavisouk C, Nakhonesid-Fish V, Strandgaard $\mathrm{H}$, Montresor A, et al. Coverage and costs of a school deworming programme in 2007 targeting all primary schools in Lao PDR. Trans R Soc Trop Med Hyg 2008;102:1201-6.

11. Bennett S, Woods T, Liyanage WM, Smith DL. A simplified general method for cluster-sample surveys of health in developing countries. World Health Stat Q 1991;44:98-106.

12. Katz N, Chaves A, Pellegrino J. A simple device for quantitative stool thick-smear technique in schistosomiasis mansoni. Rev Inst Med Trop Sao Paulo 1972;14:397-400.

13. WHO. Prevention and control of intestinal parasitic infections. Report of a WHO Expert Committee. Geneva: World Health Organization; 1987. Technical Report Series No. 749.

14. WHO. Cellophane faecal thick smear examination technique (Kato) for diagnosis of intestinal schistosomiasis and gastro intestinal helminth infections. Geneva: World Health Organization; 1993.

15. Montresor A, Crompton DWT, Bundy DAP, Hall A, Savioli L. Guidelines for the evaluation of soil-transmitted helminthiasis and schistosomiasis at community level: a guide for managers of control programmes. Geneva: World Health Organization; 1998. 
16. Filmer D, Pritchett LH. Estimating wealth effects without expenditure data-or tears: an application to educational enrollments in states of India. Demography 2001;38:115-32.

17. National Statistics Centre. Multiple indicators cluster survey and national nutrition survey. Country report. Lao PDR: UNICEF/MOH/MPI; 2006.

18. Riesel JN, Ochieng' FO, Wright P, Vermund SH, Davidson M. High prevalence of soil-transmitted helminths in Western Kenya: failure to implement deworming guidelines in rural Nyanza Province. J Trop Pediatr 2010;56:60-2.

19. Kitvatanachai S, Boonslip S, Watanasatitarpa S. Intestinal parasitic infections in Srimum suburban area of Nakhon Ratchasima Province, Thailand. Trop Biomed 2008;25:237-42.

20. Sayasone S, Vonghajack Y, Vanmany M, Rasphone O, Tesana S, Utzinger J, et al. Diversity of human intestinal helminthiasis in Lao PDR. Trans R Soc Trop Med Hyg 2009;103:247-54.

21. Stothard JR, Imison E, French MD, Sousa-Figueiredo JC, Khamis IS, Rollinson D. Soil-transmitted helminthiasis among mothers and their pre-school children on Unguja Island, Zanzibar with emphasis upon ascariasis. Parasitology 2008;135:1447-55.

22. Phathammavong O, Moazzam A, Xaysomphoo D, Phengsavanh A, Kuroiwa C. Parasitic infestation and nutritional status among schoolchildren in Vientiane, Lao PDR. J Paediatr Child Health 2007;43:689-94.

23. Kobayashi J, Vannachone B, Xeutvongsa A, Manivang K, Ogawa S, Sato $\mathrm{Y}$, et al. Prevalence of intestinal parasitic infection among children in two villages in Lao PDR. Southeast Asian J Trop Med Public Health 1996;27:562-5.

24. Hohmann H, Panzer S, Phimpachan C, Southivong C, Schelp FP. Relationship of intestinal parasites to the environment and to behavioral factors in children in the Bolikhamxay Province of Lao PDR. Southeast Asian J Trop Med Public Health 2001;32:4-13.

25. Tarafder MR, Carabin H, Joseph L, Balolong Jr E, Olveda R, McGarvey ST. Estimating the sensitivity and specificity of Kato-Katz stool examination technique for detection of hookworms, Ascaris lumbricoides and Trichuris trichiura infections in humans in the absence of a 'gold standard'. Int J Parasitol 2010;40:399-404.
26. Glinz D, N'Guessan NA, Utzinger J, N'Goran EK. High prevalence of Strongyloides stercoralis among school children in rural Côte d'Ivoire. J Parasitol 2010;96:431-3.

27. Wilhelmi I, Roman E, Sánchez-Fauquier A. Viruses causing gastroenteritis. Clin Microbiol Infect 2003;9:247-62.

28. Ezeamama AE, McGarvey ST, Acosta LP, Zierler S, Manalo DL, Wu HW, et al. The synergistic effect of concomitant schistosomiasis, hookworm, and Trichuris infections on children's anemia burden. PLoS Negl Trop Dis 2008;2:e245.

29. Lim YAL, Romano N, Colin N, Chow SC, Smith HV. Intestinal parasitic infections amongst Orang Asli (indigenous) in Malaysia: has socioeconomic development alleviated the problem? Trop Biomed 2009;26:110-22.

30. Al-Mekhlafi MS, Atiya AS, Lim YA, Mahdy AK, Ariffin WA, Abdullah $\mathrm{HC}$, et al. An unceasing problem: soil-transmitted helminthiases in rural Malaysian communities. Southeast Asian JTrop Med Public Health 2007;38:998-1007.

31. Yajima A, Jouquet P, Do TD, Dang TC, Tran CD, Orange D, et al. High latrine coverage is not reducing the prevalence of soil-transmitted helminthiasis in Hoa Binh province, Vietnam. Trans $R$ Soc Trop Med Hyg 2009;103:237-41.

32. Uga S, Hoa NT, Noda S, Moji K, Cong L, Aoki Y, et al. Parasite egg contamination of vegetables from a suburban market in Hanoi, Vietnam. Nepal Med Coll J 2009;11:75-8.

33. Zheng $\mathrm{Q}$, Chen Y, Zhang HB, Chen JX, Zhou XN. The control of hookworm infection in China. Parasit Vectors 2009;2:44.

34. Kojima S, Aoki Y, Ohta N, Tateno S, Takeuchi T. School-health-based parasite control initiatives: extending successful Japanese policies to Asia and Africa. Trends Parasitol 2007;23:54-7.

35. Knopp S, Mohammed KA, Rollinson D, Stothard JR, Khamis IS, Utzinger J, et al. Changing patterns of soil-transmitted helminthiases in Zanzibar in the context of national helminth control programs. Am J Trop Med Hyg 2009;81:1071-8.

36. Albonico M, Allen H, Chitsulo L, Engels D, Gabrielli A, Savioli L Controlling soil-transmitted helminthiasis in pre-school-age children through preventive chemotherapy. PLoS Negl Trop Dis 2008;26: e126. 